\title{
The Impact of a Book Festival on a Destination's Tourism Development
}

\author{
By Vincenzo Asero* \& Venera Tomasellit
}

\begin{abstract}
Book festivals are cultural events attracting a large number of participants, spectators and sponsorships. They are emerging worldwide as a growing sector of the tourism and leisure industries and are seen to have significant impact on the host places. Studies in tourism and hospitality management have examined the potential effects of hosting a cultural event, and revealed a variety of factors that influence the possible benefits for a destination. In many cases, the benefits lead to the repetition of the event, over the years, in the same place. These impacts have also become important factors for obtaining community-wide event support. In this regard, book festival attendance and spectators' perception may constitute opportunities for increased benefits from tourism for a host destination, enhancing the role of an event in the development of tourism. Unlike economic impacts, however, legacy and intangible impacts are somewhat difficult to evaluate. Starting from these perspectives, this research focuses on tourism impact and legacy of cultural event hosting, considering empirical evidence from a book festival in Italy.
\end{abstract}

Keywords: Event Tourism, Book Festival, Impacts Evaluation, Legacy, Multinomial Logistic Regression Models.

\section{Introduction}

Events are an important motivator of tourism as well as representing a key element in the development and marketing plans of many destinations. Hosting events has become an important element in cities' and regions' strategies in order to attract visitors and investments, providing a boost to the tourism sector (Getz 2008). According to Getz and Page (2016: 593) "events are both animators of destination attractiveness but more fundamentally as key marketing propositions in the promotion of places given the increasingly global competitiveness to attract visitor spending".

Events can be classified according to content, location, size, scope and importance. They are planned and organized in a place by different public institutions and private organizations, and may contain a number of activities (Getz 1997). Planned events can be classified primarily on the basis of their form and differences in their purpose, target and program. These typologies include cultural celebrations, political and state events, events in the arts and entertainment, business and trade, education and science, sporting competition, as well as recreational and private events (Getz 2008).

\footnotetext{
*Assistant Professor in Economics, Department of Political and Social Sciences, University of Catania, Italy.

${ }^{\dagger}$ Associate Professor in Social Statistics, Department of Political and Social Sciences, University of Catania, Italy.
} 
Events give greater economic life to the host places and raise their profile through tourism, additional trade and business development. Moreover, the impacts of events can greatly affect the quality of life of the local residents. The organization of events creates a variety of short- or long-term, positive or negative impacts, which lead to positive or negative outcomes. In this regard, literature distinguishes the term 'impact' from 'legacy'. As opposed to 'impact' the term 'legacy' is often used in a positive manner and implies after-effects, often long-term rather than immediate 'impacts'.

Despite the differences in the definitions, legacy is a multifaceted concept that encompasses tangible and intangible outcomes (Kaplanidou and Karadakis 2010). They include effects such as community pride, social cohesion, event participation, involvement of local stakeholders, enhanced destination image, increase in tourism numbers, creation of specific infrastructures and urban (re)development. Therefore, it has been argued that strategies need to be adopted in order to take control of the territorial, economic and social impacts of events, and analysis is required when looking at the impacts of each individual event.

Studies in tourism and hospitality management have examined perceived impacts from hosting an event, and revealed a variety of factors that influence evaluations of the possible benefits. A great deal of interest has centred on economic development and tourism benefits of events, with little attention paid to legacy and intangible social impacts (Li and McCabe 2013). In addition, most of the research literature on impacts is related to sporting events rather than to festivals (McCool and Lime 2001), though both sports tourism and event tourism can be considered as sub-sets of tourism in general (Deery et al. 2004).

Although economic impacts are important, exploring social impacts may have an even more substantial influence on the community (Gibson 2007). Unlike economic impacts, however, legacy and social impacts are somewhat difficult to evaluate (Kim et al. 2015) since their measurement is a very complex process. Assessing legacy impacts entails monitoring and evaluating the long-term effects of events, which is still a neglected area of research. On the other hand, social impacts are increasingly used as one of the main justifications for staging and funding events (Richards et al. 2013).

This study focuses on the experience of people attending a book festival and explores the causal relationships among spectators' satisfaction, event and host destination features, and intentions to attend a future edition of the same festival. It was hypothesized that the level of satisfaction gained by the spectators when attending the event has an impact on their intentions to attend the same festival in the future and tested whether this relationship, which is considered as a tourism legacy impact of the event, is affected by the event itself, or the place where the event is held, or both factors. The event observed is the 8th edition of Taobuk - Taormina Book Festival, an international literary festival hosted in the city of Taormina, one of the most famous tourist destinations in Sicily. 
This study supports the argument that, apart from economic impacts, there are long-term benefits from hosting an event for the place where it takes place. Thus, a better understanding of the above relationships can provide managerial insights for planning, over time, editions of events that are hosted in the same place.

\section{Conceptual Background}

Tourism development potentially provides many benefits, but these can be realized only if tourism is managed in order to keep the negative impacts to a minimum, while positive impacts are maximised. In this perspective, the issue of impacts for a destination arises when considering the effects generated by a tourist event attracting a large number of participants, spectators and sponsorships. Usually, there is a relationship between the development and marketing of events for tourism and economic development purposes. However, as Getz et el. (2007) found in their research, sometimes there is no relationship between events and tourism; this is due either to the organizers' specific aims, or limited or no interest in their tourism potential.

Many studies have found that events can have an influence on economic activities of the host destination. The attraction of many tourists is usually at the centre of analysis, since the host events attract many spectators with a high level of income and expenditure. However, the attempt to measure the impacts presents some difficulties, most significantly because of the problems of isolating the impacts of one event within a complex economy.

Apart from the economic impacts, within the literature the most frequently examined topics are community impacts, resident attitudes and perceptions. In this regard, different scholars have considered resident perceptions and host community reactions (e.g. Ritchie and Smith 1991, Soutar and McLeod 1993, Jeong and Faulkner 1996, Fredline and Faulkner 2000), revealing a variety of factors that influence resident evaluations of possible benefits and costs of event hosting. For instance, Baloglu and McClearly (1999), found that residents generally form their perceptions of hosting based on prior experiences, whereas Kim et al. (2006), have argued that attitude differences can be derived from residents' heterogeneity. Meanwhile Delamere et al. (2001) explored a wide range of non-economic benefits and costs of hosting festivals by measuring local community attitudes toward social impacts.

The impacts in the long-term for a place hosting an event can be considered in terms of legacy. The key difference relates to time, as impacts are short-term while legacies are long-term effects of the event (Masterman 2009). Preuss (2007) defines legacy as all that remains longer than the event itself, which may be considered as a consequence of the event in its environment (Chappelet 2012). According to Taksa et al. (2015), while impacts may result from strategic planning, legacy focuses on the different outcomes resulting from hosting the event. These outcomes include potential economic, tourism, social, physical, and/or environmental factors (Thomson et al. 2013). Thus, the measurement of 
legacies must consider all changes caused by an event over time, even if the most difficult part of the evaluation is the timescale when the legacies occur.

Allen et al. (2008) noted the increased importance of legacy within the event management context since the issue has become central to the decision to host or create an event. However, some authors (e.g. Matheson 2010, Thomson et al. 2013) stress that legacy is conceptualized in different ways in the academic literature as well as in the industry's practice, due to the complexities that exist around the concept. As Chappelet (2012: 26) stated, it can be seen as positive or negative, tangible or intangible, territorial or personal, intentional or unintentional, global or local and perceived from the various event stakeholders' perspectives.

Mapping the key stakeholders of an event, Jones (2010) identified as a central stakeholder the audience, that is to say, the people attending an event. This implies that taking into account audience expectations can support event organizers in making decisions and set priorities (de Prito 2013). As Oliver (1980) observed, expectations affect the experience perception after consumption in terms of satisfaction or dissatisfaction, referring the result to positive or negative feelings. Consequently, spectators' event satisfaction may affect their behavioural intention.

In tourism, the relationship among experience, satisfaction and behavioural intention is well documented (e.g. Kozak 2001, Chen and Chen 2010) even in the case of events (e.g. Shonk and Chelladular 2008, Lee and Beeler 2009, Son and Lee 2011). However, although it is recognized that tourism benefits when spectators experience a connection with the place hosting an event, the research results are different. For instance, Brown et al. (2016) explored the relationship between event satisfaction and intention to revisit a host destination among people attending the London 2012 Olympic Games, finding, in line with other studies (e.g. Kaplanidou and Vogt 2007), that the Olympic Games have not had a direct impact on intentions to revisit the host city.

In the present study, the relation between spectators' satisfaction and their intention to participate in the same event has been considered as an emotional evaluation and, therefore, a tourism legacy effect that may induce participants to repeat the experience in the future.

\section{Explaining the Choice of Attending: Data and Models}

A self-administrated questionnaire survey was conducted to collect data from spectators of Taobuk - Taormina Book Festival. The questions in the questionnaire were designed based on a review of the literature and specific characteristics of event tourism. The questionnaire was distributed by a team of research assistants at three venues which hosted events of Taobuk.

For the specific concerns of this study, some items were selected from the questionnaire in order to analyse the factors determining the tourist drawing power of the Taobuk by the following issues: 
- motivations affecting the choice to attend the 2018 edition of the festival

- level of satisfaction

- intention of attending future editions.

A preliminary study was carried out on each scheduled event of Taobuk in order to calculate the number of spectators. This analysis was aimed at ensuring the optimum representativeness, stratifying the units of analysis (the spectators) by day, place and time of each event according to a nonprobabilistic sampling procedure.

Responses from 437 spectators were used to test the statistical significance of the results. In inferential terms, the non-parametric $\chi^{2}$ test for the hypothesis of association between the variables of the database has yielded significant results with $p$-value $<0.05$, confirming the reliability of this analysis for all the audience of Taobuk.

About $70 \%$ of respondents said that they knew Taobuk, as they had already attended other editions. This seems to support the consistency of answers given to the question about the factors affecting the choice to attend 2018 Taobuk edition (Table 1).

Among these factors, the 'Typology of event' (33.7\%) is the most selected. Adding to this value the percentages expressed for factors closely linked, namely 'Notoriety' and 'Organization of Taobuk', the amount exceeds $40 \%$. Therefore, the results show that Taobuk has acquired its audience over time, while the prevalence expressed for the 'Typology of event' is a key component of its attractiveness.

Table 1. Factors of the 2018 Taobuk Edition Attending Choice

\begin{tabular}{|l|c|c|c|c|}
\hline & Frequency & \% & Valid \% & Cumulative \% \\
\hline Taormina location & 57 & 13.0 & 13.6 & 13.6 \\
\hline Typology of event & 141 & 32.3 & 33.7 & 47.4 \\
\hline Notoriety of Taobuk & 23 & 5.3 & 5.5 & 52.9 \\
\hline Organization of Taobuk & 8 & 1.8 & 1.9 & 54.8 \\
\hline Tourist services in Taormina & 3 & 0.7 & 0.7 & 55.5 \\
\hline Quality of tourist services & 2 & 0.5 & 0.5 & 56.0 \\
\hline Hospitality of Taormina & 9 & 2.1 & 2.2 & 58.1 \\
\hline Other factors & 26 & 5.9 & 6.2 & 64.4 \\
\hline $\begin{array}{l}\text { Taormina Location }+ \\
\text { Typology of event }\end{array}$ & 58 & 13.3 & 13.9 & 78.2 \\
\hline Other combinations & 91 & 20.8 & 21.8 & 100.0 \\
\hline Total & 418 & 95.7 & 100.0 & \\
\hline Missing System & 19 & 4.3 & & \\
\hline Total & 437 & 100.0 & & \\
\hline
\end{tabular}

The other important factor is 'Taormina location' (13.6\%). Also in this case, the value increases (17\%) adding other items describing Taormina as a 
tourism destination, namely 'Tourist services', 'Quality of tourist services' and 'Hospitality of Taormina'.

Even the multiple combination 'Taormina location' with 'Typology of event' reaches a percentage of $13.9 \%$, confirming the relevance of these two factors in the choice of attending Taobuk. It is clear, therefore, that Taobuk, beyond its own attractiveness, finds in Taormina an important complement to its appeal.

On the other hand, Taobuk is also an event promoting the image of Taormina as a tourist destination and can produce positive effects for the economic activities of the territorial area.

The level of satisfaction expressed by the 8th edition Taobuk audience is measured by means of a continuous scale with scores from 1 to 10 . Specifically, the higher percentages are for positions 7 (29.1\%), $8(29.7 \%)$ and $9(12.6 \%)$ of the continuum.

Since the chosen positions were largely polarized on few recurrent values, the positions were classified into three categories (Table 2): the first is low level - aggregating the scores from 1 to $5(8.5 \%)$, the second is medium level for scores 6 and 7 (40.9\%) and, finally, high level aggregating scores from 8 to $10(50.6 \%)$.

Table 2. Satisfaction Level of Expectations Related to Taobuk

\begin{tabular}{|l|c|c|c|c|}
\hline & Frequency & \% & Valid \% & Cumulative \% \\
\hline Low & 29 & 6.6 & 8.5 & 8.5 \\
\hline Medium & 139 & 31.8 & 40.9 & 49.4 \\
\hline High & 172 & 39.4 & 50.6 & 100.0 \\
\hline Total & 340 & 77.8 & 100.0 & \\
\hline Missing System & 97 & 22.2 & & \\
\hline Total & 437 & 100.0 & & \\
\hline
\end{tabular}

On the basis of the previous results, factors related to Taormina and to Taobuk were, firstly, aggregated into two variables - 'Taormina and its tourist services' and 'Taobuk and its features' - selected by $47.6 \%$ of respondents and $73.4 \%$, respectively, and then crossed with the level of satisfaction.

Figure 1. Choice Factors and Satisfaction Level

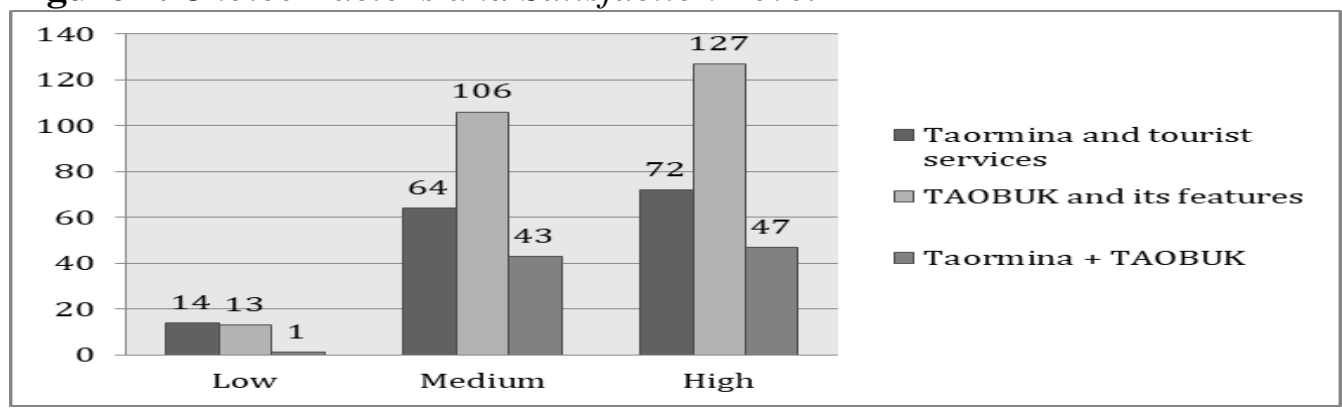


As shown in Figure 1, Taobuk is the most relevant factor in the choice of attending when the satisfaction level is medium and high.

The highest percentage (70\%) of respondents would attend future editions of the festival (Table 3), but the share of those who have not decided is relevant $(24 \%)$.

Table 3. Intention to attend Future Taobuk Editions

\begin{tabular}{|l|c|c|c|c|}
\hline & Frequency & \% & Valid \% & Cumulative \% \\
\hline Yes & 279 & 63.8 & 69.9 & 69.9 \\
\hline No & 24 & 5.5 & 6.0 & 75.9 \\
\hline I do not know & 96 & 22.0 & 24.1 & 100.0 \\
\hline Total & 399 & 91.3 & 100.0 & \\
\hline Missing System & 38 & 8.7 & & \\
\hline Total & 437 & 100.0 & & \\
\hline
\end{tabular}

Analysing the satisfaction level related to the intention to attend future editions, 'Yes' prevails (72.2\%) for the medium and high level. The higher the level of satisfaction, the more supported is the intention to attend future Taobuk editions. Hence, the highest percentage $(44.4 \%)$ of respondents who would attend future editions of the festival is the most satisfied.

The multinomial (polytomous) logistic regression (MLR) modelling is employed in the present data analysis to determine if the intention to attend future editions of Taobuk, as $Y$-dependent variable with more than two nominal or unordered categories, is affected by both the factors related to Taormina ( $X_{1^{-}}$ independent variable) or Taobuk $\left(X_{2}\right.$-independent variable) as defined above, and the satisfaction level just experienced in the 2018 edition of the festival ( $X_{3}$-independent variable).

In the present study, the relationship models proposed are based on the following main hypotheses:

- $H_{1}$ : The higher the probability of Taormina and its services to affect the intention of attending the future Taobuk editions, the higher the probability that this intention is positive;

- $\mathrm{H}_{2}$ : The higher the probability of Taobuk and its features to affect the intention of attending the future editions of the festival, the higher the probability that this intention is positive;

- $H_{3}$ : The higher the level of satisfaction for the 2018 Taobuk edition, the higher the probability of positive intention is for future editions attending;

- $H_{4}$ : The higher the probability of the interaction effect between Taormina and Taobuk, the higher the probability for positive behavioural intention is for the future.

In addition, the interaction effects both between Taormina and satisfaction levels for the 2018 Taobuk edition, and between Taobuk and the influence of 
satisfaction levels on the probability of attending future editions, have been analysed.

Furthermore, having selected the highest and the lowest satisfaction levels for 2018 Taobuk edition, the previous hypotheses are re-tested.

With the aim to test each hypothesis, MLR models are estimated, because analysis is focused on the relationships between a nonmetric dependent variable and categorical independent variables (factors). It compares multiple categories of the $Y$-dependent variable, to predict the likelihood of the categorical outcome variable given a set of $X_{n}$-independent variables (Agresti 1990).

In addition, most multivariate analysis procedures require the basic assumptions of normality and continuous data for independent and/or dependent variables. MLR is used whenever the above assumptions tend to be violated (Tabachnick et al. 2001), as in the data of the present study. MLR models are based on the probability of membership of each $n$-1 category of the $Y$ dependent variable compared to a baseline or reference category (Greene 2012). Estimating the model, the coefficients of the reference category are normalized to zero (Maddala 1990) because the probabilities for all the categories must sum up to 1 (Greene 2012).

Furthermore, in MLR two different statistics are used: the (log) likelihood ratio (often referred to as the -2 Log Likelihood or deviance) and the Wald test. In general, the likelihood ratio gives more reliable results than the Wald statistic (Hosmer and Lemeshow 2000). As a consequence, the following analysis of results is mainly focused on the likelihood ratio.

\section{Results}

In order to test if the relationship between satisfaction level for the 2018 edition and the motivations to attend Taobuk, referred either to Taormina or Taobuk or both, affects the intention to attend future editions of the festival, some multinomial logistic models were estimated.

The first model (Table 4) checks the hypothesis $H_{1}$ about the effect of Taormina on the intention to attend the future Taobuk editions. The association between the two variables is very significant $\left(\chi^{2}=280.453, p\right.$-value $<0.001$ and the measures of goodness of fit are all close to 1). The relationship between the two variables, then, likely exists and the hypothesis test about the causal effect is supported.

Using 'I do not know' as reference category for the dependent variable, the values of $\beta$-coefficients are very significant $(p$-value $<0.001)$ both in the case of intention to attend or not and also for Taormina and not Taormina. Specifically, the attending choice is related to elements not referred to Taormina ( $\beta=1.418$ for $\mathrm{TAO}=0)$ and the probability to attend $(\operatorname{Exp}(\beta)=4.128)$, is 4 times higher than for the reference category ('I do not know'), whereas for Taormina and tourist services $(\mathrm{TAO}=1)$ this probability is lower. For the relationship between the intention of not attending future editions and Taormina, the signs of $\beta$ - 
coefficients are negative in both the case Taormina (-1.079) or not Taormina (-1.872). Therefore, Taormina is not an important factor affecting the intention to attend future editions.

Table 4. Parameter Estimates of Causal Effects on Intention to attend Taobuk Future Editions ( $Y$-dependent variable) by Taormina (X-independent variable)

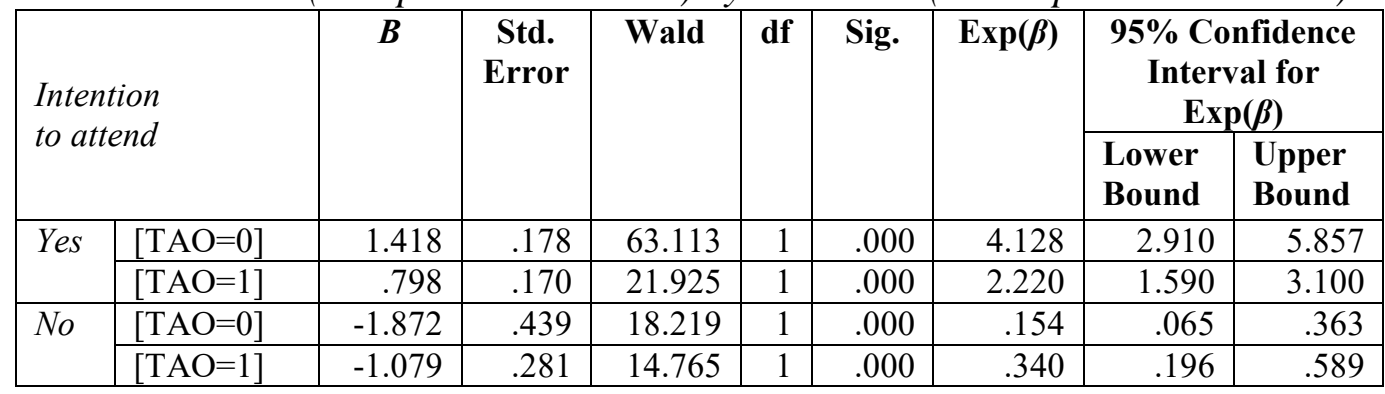

The reference category is: 'I do not know'.

\begin{tabular}{|c|c|c|c|c|c|c|c|c|c|}
\hline \multirow{2}{*}{ No } & {$[\mathrm{TAO}=0]$} & -3.290 & .416 & 62.598 & 1 & .000 & .037 & .016 & .084 \\
\cline { 2 - 10 } & {$[\mathrm{TAO}=1]$} & -1.876 & .260 & 51.901 & 1 & .000 & .153 & .092 & .255 \\
\hline $\begin{array}{c}\text { Ido } \\
\text { not } \\
\text { know }\end{array}$ & {$[\mathrm{TAO}=0]$} & -1.418 & .178 & 63.113 & 1 & .000 & .242 & .171 & .344 \\
\cline { 2 - 10 } & {$[\mathrm{TAO}=1]$} & -.798 & .170 & 21.925 & 1 & .000 & .450 & .016 & .084 \\
\hline
\end{tabular}

The reference category is: 'Yes'.

\begin{tabular}{|c|l|r|r|r|r|r|r|r|r|}
\hline \multirow{2}{*}{ Yes } & {$[\mathrm{TAO}=0]$} & 3.290 & .416 & 62.598 & 1 & .000 & 26.833 & 11.878 & 60.617 \\
\cline { 2 - 11 } & {$[\mathrm{TAO}=1]$} & 1.876 & .260 & 51.901 & 1 & .000 & 6.529 & 3.919 & 10.878 \\
\hline $\begin{array}{c}\text { Ido } \\
\text { not } \\
\text { know }\end{array}$ & {$[\mathrm{TAO}=0]$} & 1.872 & .439 & 18.219 & 1 & .000 & 6.500 & 2.752 & 15.353 \\
\cline { 2 - 10 } & {$[\mathrm{TAO}=1]$} & 1.079 & .281 & 14.765 & 1 & .000 & 2.941 & 1.696 & 5.099 \\
\hline
\end{tabular}

The reference category is: ' $\mathrm{No}$ '.

Changing the reference category ('Yes, I would like to attend the Taobuk future editions'), all the $\beta$-values are very significant and the most important relationship is negative between 'No, I will not attend' and no element referred to Taormina $(\beta=-3.290)$. Hence, the higher the probability linked to the intention of not attending, the lower the occurrence of Taormina is. Examining the 'I do not know if I will attend', the sign of $\beta$-values are negative. This result is consistent with the previous and shows that Taormina does not affect the choice to attend Taobuk.

Finally, the probability of attending is very high $(\operatorname{Exp}(\beta)=26.833)$ for the elements not related to Taormina compared to the reference category ('No'). Taormina is not very attractive but the positive intention to attend is more likely than to not attend, even if the factors are not just related to Taormina and its services. The hypothesis $H_{l}$ about the effect of Taormina on the intention to attend the future Taobuk editions is significant, but the expected causal effect is likely not due to Taormina and its services.

The second model (Table 5) checks the hypothesis $H_{2}$ about the effect of Taobuk on the intention to attend the future Taobuk editions. The association relationship between the two variables is very significant $\left(\chi^{2}=310.289, p\right.$ value< 0.001). 
Table 5. Parameter Estimates of Causal Effects on Intention to attend Taobuk Future Editions ( $Y$-dependent variable) by Taobuk (X-independent variable)

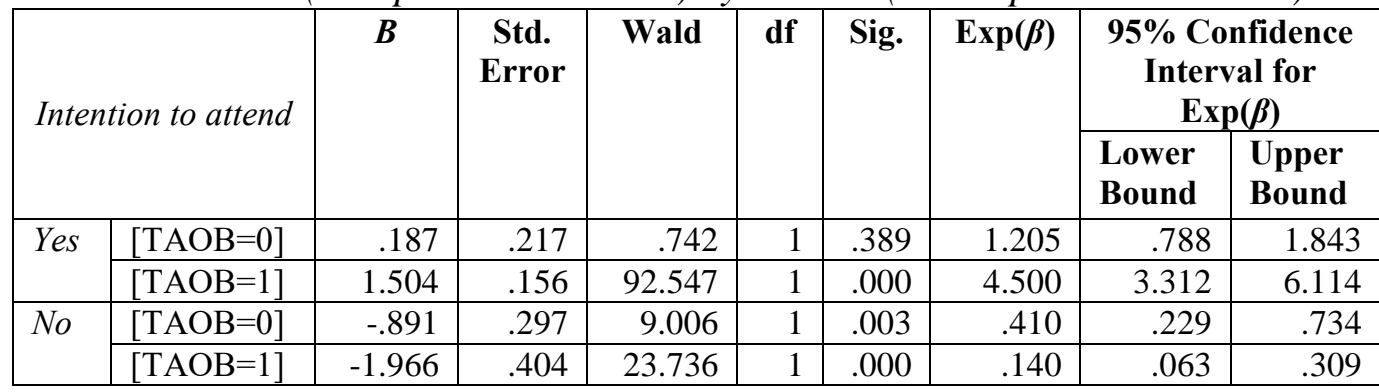

The reference category is: 'I do not know'.

\begin{tabular}{|c|r|r|r|r|r|r|r|r|r|}
\hline \multirow{2}{*}{$N o$} & {$[\mathrm{TAOB}=0]$} & -1.078 & .289 & 13.860 & 1 & .000 & .340 & .193 & .600 \\
\cline { 2 - 10 } & {$[\mathrm{TAOB}=1]$} & -3.470 & .384 & 81.752 & 1 & .000 & .031 & .015 & .066 \\
\hline $\begin{array}{c}\text { Ido } \\
\text { not } \\
\text { know }\end{array}$ & {$[\mathrm{TAOB}=0]$} & -.187 & .217 & .742 & 1 & .389 & .830 & .543 & 1.269 \\
\cline { 2 - 10 } & {$[\mathrm{TAOB}=1]$} & -1.504 & .156 & 92.547 & 1 & .000 & .222 & .164 & .302 \\
\hline
\end{tabular}

The reference category is: 'Yes'.

\begin{tabular}{|c|r|r|r|r|r|r|r|r|r|}
\hline \multirow{2}{*}{$Y e s$} & {$[\mathrm{TAOB}=0]$} & 1.078 & .289 & 13.860 & 1 & .000 & 2.938 & 1.666 & 5.180 \\
\cline { 2 - 10 } & {$[\mathrm{TAOB}=1]$} & 3.470 & .384 & 81.752 & 1 & .000 & 32.143 & 15.149 & 68.198 \\
\hline $\begin{array}{c}\text { Ido } \\
\text { not } \\
\text { know }\end{array}$ & {$[\mathrm{TAOB}=0]$} & .891 & .297 & 9.006 & 1 & .003 & 2.438 & 1.362 & 4.362 \\
\cline { 2 - 9 } & {$[\mathrm{TAOB}=1]$} & 1.966 & .404 & 23.736 & 1 & .000 & 7.143 & 3.239 & 15.754 \\
\hline
\end{tabular}

The reference category is: ' $N o$ '.

Using 'I do not know' as reference category, the value of $\beta$-coefficient is very significant $(p$-value $<0.001)$ only if the intention to attend is affected by Taobuk and its features $(\beta=1.504)$ and the positive sign shows that if the intention to attend increases/decreases, then the factor related to Taobuk also increases/decreases. The probability to attend is 4.5 times higher than the probability linked to 'I do not know' reference category, given Taobuk and its features. Taobuk, then, is a very important factor for choosing to attend the future editions of the festival. Furthermore, the choice of not attending is negatively related more to features referred to Taobuk $(\beta=-1.966)$ than no Taobuk $(\beta=-0.891)$. Then, the results show that the intention to not attend future editions is not caused by the features of Taobuk.

Assuming 'Yes' as reference category, the intention to not attend and 'I do not know' are closely related to Taobuk but the higher the probability of to not attend, the lower the probability of Taobuk as choice factor is.

Finally, with the reference category 'No, I will not attend Taobuk future editions', interesting is the $\beta=3.470$ between Taobuk and its features and the choice of attending future editions: the higher the intention to attend, the higher the probability of the occurrence of Taobuk and its features is with a probability of attending, given Taobuk, 32 times more than of not attending $(\operatorname{Exp}(\beta)=32.143)$.

The third model (Table 6) checks the hypothesis $H_{3}$ about the effect of satisfaction level for the 2018 edition on the intention to attend the future Taobuk editions. The association relationship between the two variables is high 
and very significant $\left(\chi^{2}=325.712, p\right.$-value $\left.<0.001\right)$ and the values of the indicators of goodness of fit are very close to 1 .

Table 6. Parameter Estimates of Causal Effects on Intention to attend Taobuk Future Editions (Y-dependent variable) by Satisfaction Level for the 2018 Edition (X-independent variable)

\begin{tabular}{|c|c|c|c|c|c|c|c|c|c|}
\hline \multirow{2}{*}{\multicolumn{2}{|c|}{$\begin{array}{l}\text { Intention to } \\
\text { attend } \\
\qquad \begin{array}{l}\text { Satisfaction } \\
\text { level }\end{array}\end{array}$}} & \multirow[t]{2}{*}{ B } & \multirow[t]{2}{*}{$\begin{array}{l}\text { Std. } \\
\text { Error }\end{array}$} & \multirow[t]{2}{*}{ Wald } & \multirow[t]{2}{*}{ df } & \multirow[t]{2}{*}{ Sig. } & \multirow[t]{2}{*}{$\operatorname{Exp}(\beta)$} & \multicolumn{2}{|c|}{$\begin{array}{c}95 \% \text { Confidence } \\
\text { Interval for } \\
\operatorname{Exp}(\boldsymbol{\beta}) \\
\end{array}$} \\
\hline & & & & & & & & $\begin{array}{l}\text { Lower } \\
\text { Bound }\end{array}$ & $\begin{array}{l}\text { Upper } \\
\text { Bound }\end{array}$ \\
\hline \multirow{3}{*}{ Yes } & Low & .357 & .493 & .524 & 1 & 469 & 1.429 & .544 & 3.753 \\
\hline & Medium & .862 & .193 & 19.864 & 1 & .000 & 2.368 & 1.621 & 3.460 \\
\hline & High & 1.974 & 239 & 68.435 & 1 & .000 & 7.200 & 4.510 & 11.494 \\
\hline \multirow{3}{*}{ No } & Low & .357 & .493 & .524 & 1 & 469 & 1.429 & .544 & 3.753 \\
\hline & Medium & -2.539 & .600 & 17.924 & 1 & .000 & .079 & .024 & 256 \\
\hline & High & -2.303 & .742 & 9.640 & 1 & .002 & .100 & .023 & .428 \\
\hline
\end{tabular}

The reference category is: 'I do not know'.

\begin{tabular}{|c|l|r|r|r|r|r|r|r|r|}
\hline \multirow{3}{*}{ No } & Low & .000 & .447 & .000 & 1 & 1.000 & 1.000 & .416 & 2.403 \\
\cline { 2 - 10 } & Medium & -3.401 & .587 & 33.585 & 1 & .000 & .033 & .011 & .105 \\
\cline { 2 - 10 } & High & -4.277 & .712 & 36.079 & 1 & .000 & .014 & .003 & .056 \\
\hline \multirow{2}{*}{$\begin{array}{c}\text { Ido } \\
\text { not } \\
\text { know }\end{array}$} & Low & -.357 & .493 & .524 & 1 & .469 & .700 & .266 & 1.839 \\
\cline { 2 - 10 } & Medium & -.862 & .193 & 19.864 & 1 & .000 & .422 & .289 & .617 \\
\cline { 2 - 10 } & High & -1.974 & .239 & 68.435 & 1 & .000 & .139 & .087 & .222 \\
\hline
\end{tabular}

The reference category is: 'Yes'.

\begin{tabular}{|c|l|r|r|r|r|r|r|r|r|}
\hline \multirow{3}{*}{\begin{tabular}{c} 
Yes \\
\cline { 2 - 10 }
\end{tabular}} & Low & .000 & .447 & .000 & 1 & 1.000 & 1.000 & .416 & 2.403 \\
\cline { 2 - 10 } & Hedium & 3.401 & .587 & 33.585 & 1 & .000 & 30.000 & 9.496 & 94.773 \\
\hline \multirow{2}{*}{$\begin{array}{c}\text { I do } \\
\text { not } \\
\text { know }\end{array}$} & Low & 4.277 & .712 & 36.079 & 1 & .000 & 72.000 & 17.835 & 290.662 \\
\cline { 2 - 10 } & Medium & -.357 & .493 & .524 & 1 & .469 & .700 & .266 & 1.839 \\
\cline { 2 - 10 } & High & 2.539 & .600 & 17.924 & 1 & .000 & 12.667 & 3.910 & 41.033 \\
\hline
\end{tabular}

The reference category is: 'No'.

Using 'I do not know' as reference category, the $\beta$-values are significant only for the medium and high level of satisfaction. Specifically, the high level is positively very related to intention to attend $(\beta=1.974)$ and the probability to attend is more 7 times than the reference category $\operatorname{Exp}(\beta)=7.200$. As a consequence, the more likely the intention to not attend, the lower is the satisfaction level.

Taking into account as reference category 'Yes, I would like to attend the Taobuk future editions', the significant effects of medium and high satisfaction level on the intention to not attend are negatively related. The higher the satisfaction level, the lower the probability of the intention to not attend is, as shown by the values of the odds of not attending, too.

With the 'No, I will not attend the Taobuk future editions' as reference category, the relationship between high satisfaction levels and the intention to attend is positive $(\beta=4.277)$, Remarkable are the values of the odds for high and medium satisfaction level. The intention to attend future editions, indeed, is 72 times more likely, given high level and 30 times, given the medium level, than for the 'No' reference category. 
Finally, for any reference category, the $\beta$-values for low satisfaction level are always not significant. This is likely due to the reduced number of units $(29,8.5 \%)$ classified in this level.

The hypothesis $H_{3}$ about the effect of satisfaction levels for the 2018 edition on the intention to attend the future Taobuk editions is strongly supported by the results and the causal effect is more likely due to the high than medium level.

Furthermore, in order to check $H_{4}$ for the interaction effects of Taormina and its services and also Taobuk and its features, both and separately with satisfaction levels of expectations $\left(H_{5}\right.$ and $\left.H_{6}\right)$ for the 2018 edition of Taobuk, the full factorial method employed to estimate the parameters produces no significant interaction effect, even if the Likelihood Ratio test was just significant only for $H_{5}$, Taormina and satisfaction level interaction effect (-2 Log Likelihood of Reduced Model=43.471, $p$-value<0.05).

At a subsequent stage, the same hypotheses above were checked on segment of highest level of satisfaction $\left(H_{7}\right)$. Thus, selecting only 172 subjects (50.6\% of the full sample), we obtain significant results only for the intention to attend the future Taobuk editions with $\beta$-values much more robust than the previous analysis with the full sample. The effect of Taormina is extremely interesting: on this segment, it is more evident when linked to the Taobuk effect but not significant for the interaction effect between Taormina and Taobuk, although we have checked this, too.

Finally, selecting the lowest level of satisfaction $\left(H_{8}\right)$, no significant result for any effect, likely due to the fact that there are too few subjects (29) in this segment, as also occurred for the previous model.

\section{Discussion and Conclusion}

Events are animators of destination attractiveness that attract media attention around the world, which could be a useful way to improve the hosting places' image. Numerous authors agree on the important perceived role of events in changing or enhancing the destination image of the host places (Chalip et al. 2003, Gursoy and Kendall 2006). Meanwhile, events can create a sense of values and beliefs for the tourism industry.

Events have become of interest in tourism due to the potential they offer to generate different types of impacts, among which economic and social ones are mostly emphasized by event organizers and analysed by researchers. Many studies on the impacts of events concentrate on the issue of economic impact (Kasimati 2003, Hall 2004, Richards and Wilson 2004). However, exploring social impacts may have an even more substantial importance since they are considered as key factors underpinning a rationale for investment in hosting events (Fredline et al. 2003). Hence, legacies contribute to the success of hosting events, with effects that continue into the future.

Although difficult to measure, social impacts are observed in different areas, including tourist satisfaction with the event itself (EventIMPACTS as 
cited in Li and McCabe 2013). Experience quality significantly influences satisfaction, and satisfaction affects behavioural intentions. This relationship supports the idea that "visitors with high levels of satisfaction are more likely to have an affirmative attitude of the experience, have higher intentions of revisiting a destination" (Lee and Beeler 2009: 18).

In the current study the above-cited findings seemed to be partially confirmed. Hence, spectators' 2018 edition of Taobuk satisfaction has a significant effect on their intention to attend future edition of this festival, and the causal effect is more likely in the case of high and medium levels of satisfaction. However, although the effect of Taormina, the place where Taobuk is held, on the intention to attend future editions of Taobuk is significant, the expected casual effect to repeat the experience is likely not due to Taormina and the tourist services of this destination. On the contrary, the results show that Taobuk has a direct and strong effect on the intention to attend the future edition of the festival. This may be partially explained by the fact that many people who attend an event are interested solely in the event (Osti et al. 2012).

At the same time, this study found that there is a relationship between the host place of Taormina and the level of event satisfaction. It has a particular value since Taormina plays the role of providing place identity, and is symbolic for Taobuk on many levels, from the name of the book festival to the scenic views on offer. This has an important implication for destination management, although the results showed that Taormina is not an important factor affecting the intention to attend future editions of Taobuk. This relationship is consistent with Brown et al. (2016: 169) who claim that "the benefits of investing in venues with which spectators gain a psychological connection may extend beyond the event experience to the city as a tourist destination".

These results imply that experience satisfaction may be considered as a legacy effect of Taobuk, since it can affect the spectators' intention to attend future edition of the same event. In addition, the findings suggest that a beneficial relationship may exist between the event and the destination where the event is held. Therefore, some practical strategies can be adopted by event organizers in planning future editions of Taobuk and targeting favourable event markets, reinforcing the positioning of the local tourism destination product. On the other hand, as Lee et al. (2007: 402) stated "festival organizers are likely to contend that their primary goal is to provide high quality, satisfying experiences that visitors perceive to be good value in order to increase the probability that the visitors will return in the future and/or recommend the festival to others in their social circle".

To enhance the effectiveness of such initiatives, Taobuk organizers could also be more active on social media for the collection of data to be turned into information to support decision-making processes. Hence, social media could be useful to enable the faster identification of factors influencing attendance preferences and evaluations (Ravindran et al. 2018). Thus, the use of Big Data (Boyd and Crawford 2012) through social media and digital interactions can 
provide new insights for creating new sources, beyond traditional sources of data as a natural part of event planning and management.

\section{Acknowledgements}

Financial support: Ricerca di Ateneo - Piano per la Ricerca 2016/2018.

\section{References}

Allen J, O'Toole W, Harris R, McDonnell I (2008) Festival and Special Event Management, $4^{\text {th }}$ ed. Milton, Qld: John Wiley \& Sons.

Agresti A (1990) Categorical Data Analysis. New York: John Wiley \& Sons.

Baloglu S, McCleary KW (1999) A model of destination image formation. Annals of Tourism Research 26(4): 868-897.

Boyd D, Crawford K (2012) Critical questions for big data: Provocations for a cultural, technological, and scholarly phenomenon. Information, Communication \& Society 15(5): 662-679.

Brown G, Smith A, Assaker G (2016) Revisiting the host city: An empirical examination of sport involvement, place attachment, event satisfaction and spectator intentions at the London Olympics. Tourism Management 55: 160-172.

Chalip L, Green B, Hill B (2003) Effects of sport event media on destination image and intention to visit. Journal of Sport Management 17(3): 214-234.

Chappelet J (2012) Mega sporting event legacies: A multifaceted concept. Papeles de Europa 25: 76-86.

Chen C-F, Chen F-S (2010) Experience quality, perceived value, satisfaction and behavioral intentions for heritage tourists. Tourism Management 31(1): 29-35.

de Prito MP (2013) A social responsibility scan at a major golf event in the Netherlands: Audience awareness and expectations. In G Richards, M de Brito, L Wilks (eds) Exploring the Social Impacts of Events, 126-138. Abingdon and New York: Routledge.

Deery M, Jago L, Fredline L (2004) Sport tourism or event tourism: Are they one and the same? Journal of Sport Tourism 9(3): 235-245.

Delamere TA, Wankel LM, Hinch TD (2001) Development of a scale to measure resident attitudes toward the social impacts of community festivals, Part I: Item generation and purification of the measure. Event Management 7(1): 11-24.

Fredline E, Faulkner B (2000) Host community reactions: A cluster analysis. Annals of Tourism Research 27(3): 763-784.

Fredline L, Jago L, Deery M (2003) The development of a generic scale to measure the social impacts of events. Events Management 8(1): 23-37.

Getz D (1997) Event Management and Event Tourism. New York: Cognizant Communications.

Getz D (2008) Event tourism: Definition, evolution, and research. Tourism Management 29(3): 403-428.

Getz D, Andersson T, Larson M (2007) Festival stakeholder roles: Concepts and case studies. Event Management 10(2/3): 103-122.

Getz D, Page SJ (2016) Progress and prospects for event tourism research. Tourism Management 52: 593-631. 
Gibson HJ (2007) Sport tourism. In JB Parks, J Quarterman, L Thibault (eds) Contemporary Sport Management, 141-162. Human Kinetics, Champaign, IL.

Greene W (2012) Econometric Analysis, $7^{\text {th }}$ ed. Upper Saddle River: Prentice Hall.

Gursoy D, Kendall K (2006) Hosting mega events modelling locals' support. Annals of Tourism Research 33(3): 603-623.

Hall C (2004) The definition and analysis of hallmark tourist events. GeoJournal 19(3): 263-268.

Hosmer DW, Lemeshow S (2000) Applied Logistic Regression. New York, NY: John Wiley \& Sons.

Jeong G-H, Faulkner B (1996) Resident perceptions of mega-event impacts: The Taejon International Exposition Case. Festival Management and Event Tourism 4(1-2): 3-11.

Jones M (2010) Sustainable Event Management - A Practical Guide. London: Earthscan.

Kaplanidou K, Karadakis K (2010) Understanding the legacies of host Olympic city: The case of the 2010 Vancouver Olympic Games. Sport Marketing Quarterly 19(2): 110-117.

Kaplanidou K, Vogt C (2007) The interrelationship between sport event and destination image and sport tourists' behaviours. Journal of Sport and Tourism 12(3-4): 183-206.

Kasimati E (2003) Economic aspects of the summer Olympics: A review of related research. International Journal of Tourism Research 5(6): 433-444.

Kim HJ, Gursoy D, Lee S-B (2006) The impact of the 2002 World Cup on South Korea: Comparisons of pre- and post-games. Tourism Management 27(1): 86-96.

Kim W, Jun HM, Walker M, Drane D (2015) Evaluating the perceived social impacts of hosting large-scale sport tourism events: Scale development and validation. Tourism Management 48: 21-32.

Kozak M (2001) Repeaters' behavior at two distinct destinations. Annals of Tourism Research 28(3): 784-807.

Lee J, Beeler C (2009) An investigation of predictors of satisfaction and future intention: Links to motivation, involvement, and service quality in a local festival. Event Management 13(1): 17-29.

Lee SY, Petrick JF, Crompton J (2007) The roles of quality and intermediary constructs in determining festival attendees' behavioral intention. Journal of Travel Research 45(4): 402-412.

Li S, McCabe S (2013) Measuring the socio-economic legacies of mega-events: Concepts, propositions and indicators. International Journal of Tourism Research 15(4): 388402.

Maddala GS (1990) Limited Dependent and Qualitative Variables in Econometrics. Cambridge, UK: Cambridge University Press.

Masterman G (2009) Strategic Sports Event Management: Olympic Edition, $2^{\text {nd }}$ ed. Oxford: Butterworth-Heinemann.

Matheson C (2010) Legacy planning, regeneration and events: The Glasgow 2014 Commonwealth Games. Local Economy 25(1): 10-23.

McCool SF, Lime DW (2001) Tourism carrying capacity: Tempting fantasy or useful reality?. Journal of Sustainable Tourism 9(5): 372-388.

Oliver R (1980) A cognitive model of the antecedents and consequences of satisfaction decisions. Journal of Marketing Research 17(4): 460-469.

Osti L, Disegna M, Brida JG (2012) Repeat visits and intentions to revisit a sporting event and its nearby destinations. Journal of Vacation Marketing 18(1): 31-42.

Preuss H (2007) The conceptualisation and measurement of mega sport event legacies. Journal of Sport \& Tourism 12(3-4): 207-228. 
Ravindran D, Nagamalar M, Rani DU (2018) Social media sources (SMS) influence on tourism choice decisions. Eurasian Journal of Analytical Chemistry 13(6b): 177-182.

Richards G, de Brito M, Wilks L (2013) Exploring the Social Impacts of Events. Routledge Advances in Event Research Series. Abingdon: Routledge.

Richards G, Wilson J (2004) The impact of cultural events on city image: Rotterdam, cultural capital of Europe 2001. Urban Studies 41(10): 1931-1951.

Ritchie JRB, Smith BH (1991) The impact of a mega event on host region awareness: A longitudinal study. Journal of Travel Research 30(1): 3-10.

Shonk DJ, Chelladural P (2008) Service quality, satisfaction, and intent to return in event sport tourism. Journal of Sport Management 22(5): 587-602.

Son SM, Lee K (2011) Assessing the influences of festival quality and satisfaction on visitor behavioral intentions. Event Management 15(3): 293-303.

Soutar GN, McLeod PB (1993) Resident's perceptions on impact of the America's Cup. Annals of Tourism Research 20(3): 571-582.

Tabachnick BG, Fidell LS, Osterlind SJ (2001) Using Multivariate Statistics. Boston, MA: Allyn and Bacon.

Taksa M, Chalipb L, Greenb BC (2015) Impacts and strategic outcomes from non-mega sport events for local communities. European Sport Management Quarterly 15(1): 16.

Thomson A, Schlenker K, Schulenkorf N (2013) Conceptualizing sport event legacy. Event Management 17(2): 111-122. 